\title{
Patient Satisfaction Related to Their Eye Health Examination at Lúrio University Clinic in Nampula, Mozambique during COVID-19
}

\author{
Ângela Bambamba ${ }^{\circledR}$, Joel Bambamba* ${ }^{\circledR}$, Silvia Escobar, Gisela Ferreira, Paulo Pires $\mathbb{D}^{\circledR}$, \\ Elton Langa
}

Department of Optometry, Faculty of Health Sciences, Lúrio University, Nampula, Mozambique

Email: ${ }^{\star j o e l m b a m b a m b a @ g m a i l . c o m ~}$

How to cite this paper: Bambamba, Â., Bambamba, J., Escobar, S., Ferreira, G., Pires, P. and Langa, E. (2022) Patient Satisfaction Related to Their Eye Health Examination at Lúrio University Clinic in Nampula, Mozambique during COVID-19. Open Journal of Ophthalmology, 12, 22-33.

https://doi.org/10.4236/ojoph.2022.121003

Received: October 21, 2021

Accepted: January 26, 2022

Published: January 29, 2022

Copyright $\odot 2022$ by author(s) and Scientific Research Publishing Inc. This work is licensed under the Creative Commons Attribution International License (CC BY 4.0).

http://creativecommons.org/licenses/by/4.0/

(c) (i) Open Access

\begin{abstract}
Introduction: Patient satisfaction is defined as the extent of agreement between what a patient expects to receive from his or her health experience and the perception of the level of care he or she actually receive. With the COVID-19 pandemic, many practices have to adapt to provide health ensuring patients' safety in first instance. Eye care procedures may be delayed during the pandemic, so eye safety is more important than ever, and it doesn't only focus on the examination room, all the clinic compartments must be adjusted to ensure that no patient is infected by COVID-19 within the clinic. The aim of this study was to assess the satisfaction of patients who attended the Lúrio University Clinic for eye care during COVID-19. Material and Methods: This is a quantitative, descriptive and cross-sectional study conducted from December $30^{\text {th }}$, 2020 to April $30^{\text {th }}, 2021$. A systematic random sampling method was used to enrol 173 participants. Data were collected using an identification form and the patient satisfaction survey. Ethical clearance was obtained from the Lúrio University Bioethical Committee review board, and informed consent term was also received from the participants before data collection. Results: 173 participants ( 84 women, $48.6 \%$ and 89 men, $51.4 \%$ ) completed the survey with the mean age of 31.14 and standard deviation of \pm 14 .6 years. We found that $98.3 \%$ of the participants were satisfied (63.6\% satisfied and $34.7 \%$ extremely satisfied) with the eye care provided in Lúrio University Clinic. Conclusion: Most of the patients were satisfied with the eye health examination provided in Lúrio University clinic, thus the directions for future research of the study are now opened.
\end{abstract}

\section{Keywords}

Eye Health, Lúrio University, Mozambique, Nampula, Optometry Clinic, 
Patient Satisfaction

\section{Introduction}

The emergence of the novel coronavirus disease in December 2019 halted the most occupied human society and threatened every nation. Unlike some businesses and occupations considered as essential services, Eye Care Professions (ECP) discontinued operations during the lockdown and denied many patients to mitigate the spread of COVID-19. Medical visits related to systemic and ocular diseases or injury where there is a distinguished risk of permanent vision loss because of any postponement of care, as determined by the treating ECP, are considered essential visits [1].

Therefore, access to quality healthcare is a constitutional right of every individual irrespective of race, gender, creed, and economic status [2].

The quality and adequacy of healthcare services can be measured based on patients' and their relatives' perspectives and satisfactions. Patient satisfaction is the most important indicator of the quality of care, and it is considered an outcome of healthcare services. Patient satisfaction assessment provided crucial information on performance thus contributing to total quality management [3] [4] [5].

Improved patient care has become a priority for all health care service providers with the objective of achieving a high degree of patient satisfaction. The patient's opinion is becoming more important in the improvement process of a health care delivery system. Patient satisfaction is the actual evidence of the effectiveness of the provision of healthcare services [6] [7].

Satisfaction is a unit of similarity between patient beliefs of ideal care and their observations of real care received [8]. Furthermore, patient satisfaction is the patient's perception of care received compared with the care expected or the perception and attitude that a consumer can have towards a total experience of health care, which is a multidimensional aspect and represents a vital key marker for the quality of health care delivery [9] [10] [11].

The quality of the healthcare system, as well as the health professional, is needed when examining patient satisfaction. Satisfied patients are more likely than unsatisfied ones to continue using healthcare services, maintaining their relationship with specific health care providers and complying with care regimens [12].

Indeed, patient satisfaction is a reflection of the collective efforts made by a healthcare organization. Each patient should be looked after by a team comprising physicians, nurses and other professional and administrative workers. Strong teamwork can improve the patient experience [13].

Some factors have been identified as influential to patient satisfaction in health services, including socio-demographic characteristics as gender, educational lev- 
el and length of stay in the service, as well as characteristics related to the service, perception of solving health problems and previous experience of hospitalization [14]. Furthermore, the relationship between health care providers and patients was reported to be the most influential. Meanwhile, expectation about the services, perceived adequacy of consultation duration, welcoming approach and perceived body signalling are considered as determinants of satisfaction [15].

With the known and unknown risks of COVID-19 to patients and to health care teams and the predictions of multiple models, the US Center for Disease Control and Prevention and the American Academy of Ophthalmology recommended in mid-March 2020 that physicians, including ophthalmologists, limit in-person care to urgent and emergent patients while assuming the use of appropriate personal protective equipment [16]. In addition, patients flow within clinics have also changed to observe the rules of safe distancing by spacing-out seating areas and extending gaps between appointment times to avoid overcrowding [17].

Patient satisfaction surveys are often used to understand patients' concerns and determine areas for improvement, including improving communication between health care staff and patients. Survey results document progress and allow health care staff to maintain high standards [18].

Over the past 20 years, many developed countries have been trying to include patient satisfaction surveys as a quality improvement tool in healthcare markets [19].

Patient satisfaction and the performance of healthcare providers are often interrelated events. Globally, patient satisfaction ranges from 55\% in Mozambique to $99.6 \%$ in Kuwait [20].

Although substantial research has been performed to investigate patient satisfaction with healthcare, few studies have investigated eye care through the whole examination process and within the Scenario of COVID-19 Pandemic. The aim of this study is to assess the patient satisfaction related to their eye care examination at Lúrio University Clinic in Nampula, Mozambique during COVID-19.

The research will contribute to the qualification performance of the staff working at the eye care unit of the Lúrio University Clinic, identifying favorable and unfavorable aspects of patient satisfaction, problems related to eye care, and proposing changes to improve the quality of care.

\section{Material and Methods}

A descriptive quantitative cross-sectional study was conducted from December $30^{\text {th }}, 2020$, to April $30^{\text {th }}, 2021$. Sample size was determined using a single population proportion formula. A 95\% confidence level, 5\% margin of error and 50\% anticipated patients' satisfaction levels were considered and the estimated sample size was 173. A systematic random sampling technique was employed. First, the population was ordered in such a way that each individual was uniquely identified from the number assigned to their medical record. Thus, a list was created 
that encompassed all patients. The study participants were selected by using a systematic random sampling technique with a sampling fraction of $2[\mathrm{~K}=400 / 173$ $=2$ ]. Lists of patients from the patient register of the ward were used as the sampling frame for selection.

Outpatients attending the eye care unit of Lúrio University Clinic from December 2020 to April 2021 were enrolled in the study. Patients who were not willing to participant in the study and those with any cognitive handicap were excluded.

A pre-structured questionnaire was developed by authors for current research in Portuguese and the questionnaire validity was checked by doing the pre-test in 10 patients with similar characteristics before the data collection and the content of the questionnaire was modified accordingly. Data was collected through online interviews. The questionnaire contained satisfaction indicators and socio-demographic characteristics of the patients who attended the eye care unit of Lúrio University Clinic (see Appendix 1).

The Questionnaire has 2 sections with a total of 23 items, to identify the patient's socio-demographic status and to access the level of patient satisfaction.

The level of patient satisfaction in this study was measured using 20 -item questionnaire to access Accessibility to the health care services, waiting time and satisfaction level regarding available physical facilities, services provided by the staff, provided information and regarding overall satisfaction towards the provided complete service, available physical facilities and the staff.

Each item had a 5-point Likert scale ranging from 1 (Extremely dissatisfied) to 5 (Extremely satisfied) and patient satisfaction was categorized as satisfied for participants who answered the median score, and above of the satisfaction related questions and unsatisfied, whereas those participants who answered less than or equal to the median score.

Data completeness and accuracy were checked by the study supervisor at the end of the collection. The reliability of data was checked by a reliability test and has a Cronbach's alpha value of 0.897 .

Prior to data collection, the research protocol was reviewed and approved by the Lúrio University Institutional Bioethical Review Board. The study followed the ethics guidelines of the Declaration of Helsinki (2013). Because the data were collected only by using the interviewer administered questionnaire, verbal informed consent was obtained from each of the study participants. For participants of age below 18 years, oral informed assent was taken from their parents or legal guardians and assent from themselves. The assent and verbal informed consent were approved by the Lúrio University Institutional Review board. All the study participants were informed about the purpose of the study, their right to refuse and withdraw from the study at any time. Patient confidentiality was fully protected through an anonymous questionnaire by excluding identifiers and using codes. Moreover, personal data was secured by storing data in a password-protected computer not used by others. 
The collected data were entered and analyzed using SPSS version 21 statistical software. After data cleaning was completed, descriptive statistics including frequency distribution and central tendency measures (mean, median) were used to summarize the descriptive part of the study. The median Likert scale was computed and used to identify the majority opinion to questions regarding patients' satisfaction with eye care in the Lúrio University Clinic. Statistical tests for normality such as Shapiro-will and Kolmogorov-Smirnov were performed.

\section{Results}

\subsection{Patients' Socio-Demographic Characteristics}

This study enrolled 173 (84 women, 48.6\% and 89 men, 51.4\%) patients who were treated in eye care unit at Lúrio University Clinic. Users' age ranged from 15 to 70 years, with a mean of 31.1 and Standard Deviation (SD) of \pm 14.5 years. The profile of the interviewed patients is given in Table 1.

Young adults accounted for the highest percentage 115 (66.5\%) of respondents and $84(48.6 \%)$ were attending or had already completed higher education.

\subsection{Patient Satisfaction Predictors Rates about Eye Care at Lúrio University Clinic}

The level of patient satisfaction in this study was measured by assessing three dimensions: service utilization, patient and health care provider interaction, and facility-related information. The information is summarized in Table 2.

Patient reported to be extremely satisfied with the kindness of the Optometrist 77 (44.5\%), the Optometry respect 86 (49.7\%), kindness of the receptionist 61 (35.3\%) and Comfort of the environment where was performed the consultation and/or treatment 62 (35.8\%). Excitement of satisfaction raised to the level of Satisfied with regarding of Clarification of doubts 61 (35.3\%), Opportunity to express your opinion 61 (35.3\%), Deepness of assessment $66(38.2 \%)$, Clarity in explanations 61 (35.3\%), Kindness of the team 66 (38.2\%), Waiting room comfort $57(32.9 \%)$ and General hygiene conditions of the clinic 64 (37.0\%). The Fair Grade was attributed to Safety during eye examination 60 (34.7\%), Privacy 63 (36.4\%), Ease of booking the first appointment 72 (41.6\%), Ease of scheduling sessions after the first appointment 76 (43.9\%), Availability of convenient times to carry out the treatment 79 (45.7\%), Length of stay in the waiting room after the scheduled time 68 (39.3\%), Convenience of the clinic location 69 (39.9\%), Parking availability 103 (59.5\%) and Ease of transit within the clinical facilities 71 (41.0\%).

\subsection{Patients' Overall Satisfaction with Eye Care Services at Lúrio University Clinic}

The information regarding overall patients' satisfaction, those examined in the eye care unit of the Lúrio University Clinic is summarized in Table 3. In this study $91(52.6 \%)$ patients were satisfied with their eye care and $82(47.4 \%)$ were dissatisfied, with the mean value of 77.8 for overall satisfaction. 
Table 1. Sample' socio-demographic characteristics.

\begin{tabular}{ccc}
\hline Variables & n (\%) \\
\hline Teenager $(13-19)$ & Agroup & \\
Young adult $(20-39)$ & $12(6.9 \%)$ \\
Middle-age $(40-59)$ & $115(66.5 \%)$ \\
Elderly $(>60)$ & $31(17.9 \%)$ \\
\hline Male & Gender & $15(8.7 \%)$ \\
\hline Female & & \\
\hline \multicolumn{1}{c}{ Education } & $89(51.4 \%)$ \\
\hline High school completed & $12(6.9 \%)$ \\
Tertiary education completed & $77(44.5 \%)$ \\
\hline
\end{tabular}

Table 2. Patient' satisfaction indicators regarding eye care at Lúrio university clinic.

\begin{tabular}{|c|c|c|c|c|c|c|}
\hline Satisfaction indicators & $\begin{array}{l}\text { Extremely } \\
\text { satisfied }\end{array}$ & Satisfied & Fair & Dissatisfied & $\begin{array}{l}\text { Extremely } \\
\text { dissatisfied }\end{array}$ & Mean (SD) \\
\hline Safety during eye examination & $55(31.8 \%)$ & $57(32.9 \%)$ & $60(34.7 \%)$ & $1(0.6 \%)$ & $0(0.0 \%)$ & $3.96(0.83)$ \\
\hline Clarification of doubts & $53(30.6 \%)$ & $61(35.3 \%)$ & $57(32.9 \%)$ & $1(0.6 \%)$ & $1(0.6 \%)$ & $3.95(0.84)$ \\
\hline Kindness of the optometrist & $77(44.5 \%)$ & $65(37.6 \%)$ & $31(17.9 \%)$ & $0(0.0 \%)$ & $0(0.0 \%)$ & $4.27(0.75)$ \\
\hline Optometrist respect & $86(49.7 \%)$ & $54(31.2 \%)$ & $33(19.1 \%)$ & $0(0.0 \%)$ & $0(0.0 \%)$ & $4.31(0.77)$ \\
\hline Privacy & $58(33.5 \%)$ & $49(28.3 \%)$ & $63(36.4 \%)$ & $2(1.2 \%)$ & $1(0.6 \%)$ & $3.93(0.89)$ \\
\hline Opportunity to express your opinion & $51(29.5 \%)$ & $61(35.3 \%)$ & $58(33.5 \%)$ & $2(1.2 \%)$ & $1(0.6 \%)$ & $3.92(0.85)$ \\
\hline Deepness of assessment & $55(31.8 \%)$ & $66(38.2 \%)$ & $50(28.9 \%)$ & $2(1.2 \%)$ & $0(0.0 \%)$ & $4.01(0.81)$ \\
\hline Clarity in explanations & $59(34.1 \%)$ & $61(35.3 \%)$ & $51(29.5 \%)$ & $2(1.2 \%)$ & $0(0.0 \%)$ & $4.01(0.86)$ \\
\hline Kindness of the team & $60(34.7 \%)$ & $66(38.2 \%)$ & $46(26.6 \%)$ & $1(0.6 \%)$ & $0(0.0 \%)$ & $4.06(0.79)$ \\
\hline Kindness of the receptionist & $61(35.3 \%)$ & $61(35.3 \%)$ & $50(28.9 \%)$ & $1(0.6 \%)$ & $0(0.0 \%)$ & $4.05(0.81)$ \\
\hline Ease of booking the first appointment & $56(32.4 \%)$ & $43(24.9 \%)$ & $72(41.6 \%)$ & $1(0.6 \%)$ & $1(0.6 \%)$ & $3.88(0.89)$ \\
\hline $\begin{array}{l}\text { Ease of scheduling sessions after the first } \\
\text { appointment }\end{array}$ & $49(28.3 \%)$ & $45(26.0 \%)$ & $76(43.9 \%)$ & $2(1.2 \%)$ & $1(0.6 \%)$ & $3.8(0.88)$ \\
\hline $\begin{array}{l}\text { Availability of convenient times to carry out } \\
\text { the treatment (e.g., visual therapies) }\end{array}$ & $44(25.4 \%)$ & $45(26.0 \%)$ & $79(45.7 \%)$ & $4(2.3 \%)$ & $1(0.6 \%)$ & $3.73(0.88)$ \\
\hline $\begin{array}{l}\text { Length of stay in the waiting room after the } \\
\text { scheduled time }\end{array}$ & $37(21.4 \%)$ & $52(30.1 \%)$ & $68(39.3 \%)$ & $14(8.1 \%)$ & $2(1.2 \%)$ & $3.62(0.94)$ \\
\hline Convenience of the clinic location & $28(16.2 \%)$ & $46(26.6 \%)$ & $69(39.9 \%)$ & $19(11.0 \%)$ & $11(6.4 \%)$ & $3.35(1.07)$ \\
\hline Parking availability & $20(11.6 \%)$ & $41(23.7 \%)$ & $103(59.5 \%)$ & $3(1.7 \%)$ & $6(3.5 \%)$ & $3.38(0.84)$ \\
\hline Waiting room comfort & $45(26.0 \%)$ & $57(32.9 \%)$ & $55(31.8 \%)$ & $1(8.1 \%)$ & $2(1.2 \%)$ & $3.75(0.97)$ \\
\hline $\begin{array}{l}\text { Comfort of the environment where was } \\
\text { performed the consultation and/or treatment } \\
\text { (e.g., visual therapy) }\end{array}$ & $62(35.8 \%)$ & $52(30.1 \%)$ & $58(33.5 \%)$ & $1(0.6 \%)$ & $0(0.0 \%)$ & $4.01(0.84)$ \\
\hline
\end{tabular}




\section{Continued}

\begin{tabular}{lllllll}
\hline General hygiene conditions of the clinic & $63(36.4 \%)$ & $64(37.0 \%)$ & $46(26.6 \%)$ & $0(0.0 \%)$ & $0(0.0 \%)$ & $4.1(0.79)$ \\
Ease of transit within the clinical facilities & $34(19.7 \%)$ & $64(37.0 \%)$ & $71(41.0 \%)$ & $4(2.3 \%)$ & $0(0.0 \%)$ & $3.74(0.79)$ \\
\hline
\end{tabular}

Note: $\mathrm{SD}=$ Standard Deviation.

Table 3. Patients attended at Lúrio university clinic overall satisfaction.

\begin{tabular}{ccc}
\hline Overall Satisfaction & $\mathbf{n}(\%)$ & Mean \\
Satisfied & $91(52.6 \%)$ & \\
Dissatisfied & $82(47.4 \%)$ & 77.8 \\
\hline
\end{tabular}

\section{Discussion}

Overall patient' satisfaction towards eye care provided by the Lúrio University Clinic was assessed using a 20 -item patient satisfaction questionnaire.

We found that $52.6 \%$ of patients were satisfied with eye health services received, a similar result was demonstrated in the study conducted in the National Institute of Ophthalmology in Vietnam (50\%) and in Himalaya Eye Hospital in Nepal (51.2\%) [21] [22].

Different results were found in other studies conducted in the Department of Ophthalmology, Nepal Medical College Teaching Hospital (76.8\%), Susrut Eye Hospital in India (85.0\%), and Department of Ophthalmology in the Southwest Ethiopia (97.8\%) [23] [24] [25].

Patient experience is now widely accepted as a health care measure and component of health care quality, which is used by both health care systems and the public for evaluating physician performance. Furthermore, the marketing available statistics may impact patient referrals or a patient's practice selection for elective procedures. Patient' satisfaction rates vary among medical specialties and are affected by several individual visit characteristics [26].

In our sample, patients reported to be extremely satisfied with the Kindness of the Optometrist (44.5\%), Optometrist Respect (49.7\%), Kindness of the team (34.7\%), Kindness of the receptionist (35.3\%), Comfort of the environment where was performed the consultation and/or treatment (35.8\%) and General hygiene conditions of the clinic (36.4\%).

The reliability analysis for the patient satisfaction measurement items resulted in a overall Cronbach's Alpha score of 0.897 which tells that the scale demonstrated adequate validity and moderate reliability, and therefore, this scale can be recommended for future research studies of patient' satisfaction with eye care.

This is the first study assessing patient' satisfaction towards eye care in Mozambique, providing front-line researchers with a reliable method of measuring patient' satisfaction, and identifying potential sources of dissatisfaction within the eye care unit as well as the possible associated factors of satisfaction, wiliness of return for follow-ups and intention of recommendation for friends and relatives. 


\section{Limitation and Strength of the Study}

Patient satisfaction can be accessed based on such assessment data. However we understand that there may be potential confounding factors that we did not take into account neither in data collection tools preparation nor in the analysis. Patients with different clinical presentations might have different satisfaction rates, and also the severity of cases may influence satisfaction rates.

In addition, the association between socio-demographic Characteristics of the patients with the satisfaction rate, the patient recommendations to improve our services, the willing to return to the clinic and/or recommend the clinic services was not accessed. Furthermore there are no standard procedures or tools to assess patient satisfaction related to eye health examination in Mozambique.

As strength of this study, it is the first study to be conducted in Mozambique to access patient satisfaction related to eye health examination and this would have a great input for the whole staff at the Lúrio University clinic and quality improvement in terms of identifying potential areas of improvements and plan strategies of the care provided.

\section{Conclusions}

More than half of the patients were satisfied with the overall eye health care received at the Lúrio University eye clinic.

The higher remarkable indicator of dissatisfaction level was linked to the eye clinic location. Distinguished determinant factors of patient satisfaction identified were kindness and respect of the optometrist during the eye examination. It is important that the university and the clinic staff work together to build marketing strategies to mitigate the influence of the clinic location in the patients' satisfaction rate.

\section{Acknowledgements}

We acknowledge Lúrio University for providing the opportunity to conduct this research and respondents who participated in this study.

\section{Conflicts of Interest}

The authors declare they have no conflicts of interest.

\section{References}

[1] Ekpenyong, B., Obinwanne, C.J., Ovenseri-Ogbomo, G., Ahaiwe, K., Lewis, O.O., Echendu, D.C. and Osuagwu, U.L. (2020) Assessment of Knowledge, Practice and Guidelines towards the Novel COVID-19 among Eye Care Practitioners in Nigeria-A Survey-Based Study. International Journal of Environmental Research and Public Health, 17, Article No. 5141. https://doi.org/10.3390/ijerph17145141

[2] Ogunlade, A.A., Ayandiran, E.O., Oyediran, O.O., Oyelade, O.O. and Olaogun, A.A. (2020) Quality of Emergency Nursing Care in Two Tertiary Healthcare Settings in a Developing Sub-Saharan African Country. African Journal of Emergency Medicine, 10, S73-S77. https://doi.org/10.1016/j.afjem.2020.05.008 
[3] Karaca, A. and Durna, Z. (2019) Patient Satisfaction with the Quality of Nursing Care. Nursing Open, 6, 535-545. https://doi.org/10.1002/nop2.237

[4] Kruse, C.S., Krowski, N., Rodriguez, B., Tran, L., Vela, J. and Brooks, M. (2017) Telehealth and Patient Satisfaction: A Systematic Review and Narrative Analysis. BMJ Open, 7, Article ID: e016242. https://doi.org/10.1136/bmjopen-2017-016242

[5] Smail, A., Gan, Y.N. and Ahmad, N. (2020) Factors Associated with Patient Satisfaction towards Pharmacy Services among Out-Patients Attending Public Health Clinics: Questionnaire Development and Its Application. PLoS ONE, 15, Article ID: e0241082. https://doi.org/10.1371/journal.pone.0241082

[6] Manzoor, F., Wei, L., Hussain, A., Asif, M. and Shah, S.I.A. (2019) Patient Satisfaction with Health Care Services: An Application of Physician's Behavior as a Moderator. International Journal of Environmental Research and Public Health, 16, Article No. 3318. https://doi.org/10.3390/ijerph16183318

[7] Perneger, T.V., Peytremann-Bridevaux, I. and Combescure, C. (2020) Patient Satisfaction and Survey Response in 717 Hospital Surveys in Switzerland: A Cross-Sectional Study. BMC Health Services Research, 20, Article No. 158.

https://doi.org/10.1186/s12913-020-5012-2

[8] Deriba, B.S., Geleta, T.A., Beyane, R.S., Mohammed, A., Tesema, M. and Jemal, K. (2020) Patient Satisfaction and Associated Factors during COVID-19 Pandemic in North Shoa Health Care Facilities. Patient Prefer Adherence, 14, 1923-1934. https://doi.org/10.2147/PPA.S276254

[9] Asamrew, N., Endris, A.A. and Tadesse, M. (2020) Level of Patient Satisfaction with Inpatient Services and Its Determinants: A Study of a Specialized Hospital in Ethiopia. Journal of Environmental and Public Health, 2020, Article ID: 2473469. https://doi.org/10.1155/2020/2473469

[10] Abidova, A., da Silva, P.A. and Moreira, S. (2020) Predictors of Patient Satisfaction and the Perceived Quality of Healthcare in an Emergency Department in Portugal. Western Journal of Emergency Medicine, 21, 391-403. https://doi.org/10.5811/westjem.2019.9.44667

[11] Adissu, G., Biks, G.A. and Tamirat, K.S. (2020) Patient Satisfaction with Antiretroviral Therapy Services and Associated Factors at Gondar Town Health Centers, Northwest Ethiopia: An Institution-Based Cross-Sectional Study. BMC Health Services Research, 20, Article No. 93. https://doi.org/10.1186/s12913-020-4934-z

[12] Hooker, R.S., Moloney-Johns, A.J. and McFarland, M.M. (2019) Patient Satisfaction with Physician Assistant/Associate Care: An International Scoping Review. Human Resources for Health, 17, Article No. 104. https://doi.org/10.1186/s12960-019-0428-7

[13] Xiong, C., Chen, X., Zhao, X. and Liu, C. (2018) Patient Satisfaction and Gender Composition of Physicians-A Cross-Sectional Study of Community Health Services in Hubei, China. BMC Health Services Research, 18, Article No. 217. https://doi.org/10.1186/s12913-018-3011-3

[14] Levandovski, P.F., Lima, M.A.D.S. and Acosta, A.M. (2015) Patient Satisfaction with Nursing Care in an Emergency Service. Investigación y Educación en Enfermería, 33, 473-481.

[15] Worku, M. and Loha, E. (2017) Assessment of Client Satisfaction on Emergency Department Services in Hawassa University Referral Hospital, Hawassa, Southern Ethiopia. BMC Emergency Medicine, 17, Article No. 21.

https://doi.org/10.1186/s12873-017-0132-7

[16] Elam, A.R., Ehrlich, J.R. and Lee, P. (2020) Insights into Eye Care Practice during 
COVID-19. JAMA Ophthalmology, 138, 988-989.

https://doi.org/10.1001/jamaophthalmol.2020.3244

[17] Teo, K.Y.C., Chan, R.V.P. and Cheung, C.M.G. (2020) Keeping Our Eye care Providers and Patients Safe during the COVID-19 Pandemic. Eye, 34, 1161-1162.

https://doi.org/10.1038/s41433-020-0960-7

[18] Acharya, S., Ghimire, C., Shrestha, A., Yadav, A.K. and Bhandari, S. (2019) Patient Satisfaction with Nursing Care in Five Major Departments in a Tertiary Care Centre. Journal of Nepal Medical Association, 57, 367-370. https://doi.org/10.31729/jnma.4643

[19] Hu, L., Ding, H., Liu, S., Wang, Z., Hu, G. and Liu, Y. (2020) Influence of Patient and Hospital Characteristics on Inpatient Satisfaction in China's Tertiary Hospitals: A Cross-Sectional Study. Health Expectations, 23, 115-124. https://doi.org/10.1111/hex.12974

[20] Geberu, D.M., Biks, G.A., Gebremedhin, T. and Mekonnen, T.H. (2019) Factors of Patient Satisfaction in Adult Outpatient Departments of Private Wing and Regular Services in Public Hospitals of Addis Ababa, Ethiopia: A Comparative Cross-Sectional Study. BMC Health Services Research, 19, Article No. 869.

https://doi.org/10.1186/s12913-019-4685-x

[21] Huy, N.V., Dung, N.N., Thang, C.D. and Hanh, L.T. (2018) Patient Satisfaction with Health Care Services at a National Institute of Ophthalmology. The International Journal of Health Planning and Management, 33, e251-e62. https://doi.org/10.1002/hpm.2449

[22] Tiwari, S., Bhatta, B. and Wagle, S. (2021) Satisfaction among the Patients Attending Himalaya Eye Hospital, Pokhara, Nepal. Journal of Health and Allied Sciences, 11, 38-42. https://www.jhas.org.np/jhas/index.php/jhas/article/view/137

[23] Rizyal, A. (2012) Patients' Satisfaction with Eye Care Services at Nepal Medical College. Nepal Medical College Journal, 14, 172-175.

[24] Dudhamal, V.B., Solanke, P., Berad, A. and Sadanandam, V. (2021) An Assessment of Patient Satisfaction in Outpatient Department of an Eye Care Hospital. European Journal of Molecular \& Clinical Medicine, 7, 5486-5493.

[25] Yeshigeta, G.B., Aemero, A., Tsedeke, A. and Abateneh, A. (2015) Patients' Satisfaction with Outreach Eye Care Service Provided in South West Ethiopia. Journal of Ophthalmology of Eastern Central and Southern, 19, 69-74.

[26] Smith, W.R., Wera, J., Ramsey, F.V., Takei, R., Gallant, G., Liss, F., Beredjiklian, P. and Kwok, M. (2019) Patient Satisfaction in the Preoperative Period: Preparing for Hand Surgery. HAND, 14, 646-650. https://doi.org/10.1177/1558944718760036 


\section{Appendix 1}

Questionnaire

\section{Confidential For Research Purpose Only}

Patient satisfaction related to their eye health examination at Lúrio University Clinic in Nampula, Mozambique during COVID-19.

Gender

Age (Years)

Education Level

Primary Education Completed

High School Completed

Tertiary Education Completed

\section{Patient Satisfaction}

For the following items, we ask you to indicate only one number that corresponds to your level of satisfaction, as follows: 1 . Extremely Dissatisfied; 2. Dissatisfied; 3. Fair; 4. Satisfied; 5. Extremely Satisfied

Safety during eye examination

1

2

3

4

5

Clarification of doubts

1

2

3

4

5

Kindness of the Optometrist

Optometrist Respect

1

2

3

4

Privacy during eye examination

2

3

4

5

Opportunity to express your opinion

1

2

3

4

5

Deepness of assessment

1

2

3

4

5

Clarity in explanations

1

2

$$
3
$$

4

5

Kindness of the team

1

2

3

4

5

Kindness of the receptionist

1

2

3

4

5

Ease of booking the first appointment

1

2

3

4

5

Ease of scheduling sessions after the first appointment

2

3

4 5 


\section{Continued}

Availability of convenient times to carry out the treatment

3

4

5

Length of stay in the waiting room after the scheduled time

1

2

3

4

Convenience of the clinic location

1

4

Parking availability

1

2

3

4

5

Waiting room comfort

1

2

4

Comfort of the environment where was performed the consultation and/or treatment (e.g., visual therapy)

2

3

4

General hygiene conditions of the clinic

1

2

3

4

5

Ease of transit within the clinical facilities

2

3

4

5

\section{The End.}

